\title{
Progress in Theory and Practice of Government Functional Transformation in the Context of the Reform of "Delegating Power, Strengthening Regulation, Improving Government Services"
}

\author{
Yazhuo Huang \\ Zhou Enlai School of Government, Nankai University, Tianjin, China \\ Email: hyz1130@163.com
}

How to cite this paper: Huang, Y. Z. (2020). Progress in Theory and Practice of Government Functional Transformation in the Context of the Reform of "Delegating Power, Strengthening Regulation, Improving Government Services". Open Journal of Social Sciences, 8, 202-209.

https://doi.org/10.4236/jss.2020.85014

Received: April 22, 2020

Accepted: May 16, 2020

Published: May 19, 2020

Copyright $\odot 2020$ by author(s) and Scientific Research Publishing Inc. This work is licensed under the Creative Commons Attribution International License (CC BY 4.0).

http://creativecommons.org/licenses/by/4.0/

\begin{abstract}
Since the 19th Communist Party of China National Congress, in order to meet the development requirements of the "new era", the practice and research on government functional transformation in the context of the reform of "Delegating Power, Strengthening Regulation, Improving Government Services" has gradually become an important topic. This article will review the theory and practice of government functional transformation in the context of the "Delegating Power, Strengthening Regulation, Improving Government Services", and review its theoretical and practical progress, as well as its future trends.
\end{abstract}

\section{Keywords}

Delegating Power, Strengthening Regulation, Improving Government Services, Government Functional Transformation, Research Status, Practice Progress

\section{Research Progress on the Government Functional Transformation in the Context of the Reform of “Delegating Power, Strengthening Regulation, Improving Government Services"}

The research on the government's functional transformation in the context of the reform of "Delegating Power, Strengthening Regulation, Improving Government Services" is in its infancy. Using "theme = government functional transformation" and including "theme = Delegating Power, Strengthening Regulation, Improving Government Services" as a search condition, search on CNKI to obtain literature. There are a total of 53 articles, including 13 high-level doc- 
uments (core journals, CSSCI). From the perspective of the scale of research, the amount of literature is increasing year by year. From the research field, the literature involves multiple fields such as public management, political reform, market economy, and higher education. From the research content, the literature includes many topics such as government services, administrative approval, business environment, power and responsibility list, and public services. Specifically, the current domestic researches mainly focus on the following two levels.

First, macro-focused on the reform. Scholars generally believe that "Delegating Power, Strengthening Regulation, Improving Government Services" is the core content and basic direction. The first moves and breakthroughs to promote the transformation of government functions have become the basic consensus of most scholars. The second is to microscopically advocate "administrative examination and approval system reform", "Internet+ government services", etc. Most scholars believe that the implementation of government functional transformation in the context of the reform of "Delegating Power, Strengthening Regulation, Improving Government Services" is mainly reflected through the reform of the administrative approval system, Internet+ government service and other institutional innovations as well as technological innovations. Therefore, "system + technology" undoubtedly drives the deepening of the reform, and has become the foothold and accelerator of the transformation of government functions.

However, it is regrettable that the research on the transformation of government functions in the context of the "Delegating Power, Strengthening Regulation, Improving Government Services" reform is still somewhat inadequate and cannot fully respond to practical confusion. First, although the research topics are becoming more and more abundant, the depth is still lacking. The discussion of many documents stems from the summary of experience, and fails to deeply analyze the driving mechanism and institutional dilemma of government functional transformation from the theoretical construction level. Second, although the standard of research is constantly improving, the method is relatively simple. Most of the literature outlines the general face of the transformation of government functions in the context of the reform of "Delegating Power, Strengthening Regulation, Improving Government Services" along the lines of "what-why-how" or "problem-cause-measures". Very few studies have dug into empirical materials in depth, and have used case studies, comparative studies, inductive studies, and other methods to conduct scientific analysis and systematic discussion of problems.

\section{Practical Exploration of Government Functional Transformation in the Context of the Reform of “Delegating Power, Strengthening Regulation, Improving Government Services"}

\subsection{Delegating Power Is the Starting Point for Government Functional Transformation}

Delegating power refers to the government clarifying the boundaries of func- 
tions and promoting the transformation of functions by canceling government affairs that can be cancelled. In recent years, the central government and local governments have successively implemented a series of reform measures to do subtraction for the government and add vitality to the market. First, the reform of the administrative examination and approval system. The State Council has cancelled, decentralized and adjusted 670 department approval items in 10 batches, fulfilling the State Council's target of reducing the approval items by $1 / 3$ in advance and exceeding; completely eliminating non-administrative license approval categories, reducing "system backdoors" and "interest sharing" Space; cancel 305 items designated by the central government to implement administrative licensing, and clear up 323 items of intermediary services for administrative examination and approval by the State Council (Xinhuanet, 2017b). Second, the reform of the commercial system. On the one hand, the industrial and commercial registration was changed from "pre-licensed and then photo" to "first and then certificate", and 196 items of pre-approval for industrial and commercial registration were changed to post-approval; On the other hand, the registered capital was changed from the "actual payment system" to the "subscription system", and the registered capital of the industrial and commercial department was changed to the amount of capital subscribed by the company's shareholders (Xinhua News Agency, 2017).

\subsection{Strengthening Regulation Is the Guarantee for Government Functional Transformation}

Strengthening regulation means that the government promotes the transformation of government functions through the innovation of management concepts and supervision methods, and creates a transparent, fair, and good competitive environment for market players. First, change management philosophy. The central government and local governments continue to increase their awareness of supervision and gradually change the concept of supervision, greatly reducing the phenomenon of "approval infatuation" such as "emphasis on approval" and "approval will not control". Second, innovative supervision methods. On the one hand, change the traditional "penalty-based" supervision method, establish a new credit-based supervision mode, adopt credit grading and classification supervision according to credit ratings, and use big data, "Internet+" and other technical means to achieve full coverage of "pre-event, mid-event, and post-event" supervision, reducing supervision costs while improving supervision efficiency and effectiveness. On the other hand, strengthen the vertical level of supervision, strengthen the vertical supervision of the central government for national or cross-regional affairs; strengthen the supervision of the central government for central and local co-administration affairs, and promote all levels of government departments to perform their duties according to law. And then promote the formation of a unified national market and unified legal system (Shen, 2018). 


\subsection{Improving Government Services Is the End of Government Functional Transformation}

Improving government services means that the government insists on "people-centeredness", solves the most direct, realistic and practical interest issues of the people, continuously enhances the people's sense of gain and improves the satisfaction of the government's work. First, the implementation of "Internet+ government services". Central government departments and local governments at all levels actively responded to the deployment of the State Council and established a government service platform and an online government service system in accordance with the requirements of "should be on top and online throughout". According to statistics, there are now about 30 government service platforms of the State Council and 31 provincial government service platforms; about 20 regions have established online government service systems at or above the provincial, municipal and county levels (China Information Network, 2019). Second, the construction of the Administrative Examination Bureau model. Since 2015, the administrative examination and approval bureau model has been promoted and implemented nationwide. According to statistics, there are now 21 provinces that have carried out relatively centralized reforms of administrative licensing rights, with a total of 368 pilots, including 65 prefecture-level (including 16 in Tianjin), and 257 counties (cities, districts, and flags) There are 49 development zones (parks) of various types (National Business Organization, 2019).

\section{Realistic Obstacles to Government Functional Transformation in the Context of the Reform of "Delegating Power, Strengthening Regulation, Improving Government Services"}

\subsection{The Obstacles in Government-Government}

On the one hand, the government has generally focused its attention on "Delegating Power", vigorously promoting the reform of the administrative examination and approval system, the reform of the commercial system, and the reform of the examination and approval procedures, in an effort to fit the higher-level assessment guidance of "GDP first" and the local interests of "development-oriented" claim. The selective implementation or alternative implementation of reforms such as "Strengthening Regulation" and "Improving Government Services" has resulted in shortcomings such as inadequate regulatory systems, weak regulatory power, backward government services, and unregulated intermediary services. The top-level design of the "Delegating Power, Strengthening Regulation, Improving Government Services" reform cannot be effectively implemented, and the good wishes for the transformation of government functions cannot be successfully realized. On the other hand, the process of government functional transformation in the context of the reform of "Delegating Power, Strengthening Regulation, Improving Government Services" lacks an 
authoritative and powerful coordination mechanism, making it difficult to coordinate task objectives and monitor the implementation effect. This has led to the entanglement of "delegation", "regulation" and "service" of government responsibilities, Unreasonable, unable to comprehensively and systematically think about the reform direction and reform process.

\subsection{The Obstacles in Government-Market}

With the deepening of the reform of the tax sharing system and the reform of administrative decentralization and the popularity of the championships around the GDP performance promotion, the pursuit of rapid economic development and the promotion of officials have become an inevitable choice for local governments. Administrative and fiscal decentralization reforms have triggered fierce competition among local governments to compete for and protect tax sources. On the one hand, local protectionism and market segmentation have become popular. On the other hand, local governments have been forced to take risks and intervene in market activities. In addition, under the structure of the tournament that is eliminated step by step, the government officials in the promotion sequence, in order to "not fall behind" and achieve rapid promotion, all put a lot of energy and financial resources into areas that can quickly produce results to achieve GDP and related economies. The improvement of the indicators thus encourages the "short-sighted" behavior strategy of local government officials, so that they only care about real interests and ignore long-term interests. In this way, the local governments that have made quick successes not only play the role of "referee" to maintain market order, but also use the status of "referee" to compete with businessmen and gain profits from the people, making government functions "large and small" and difficult to change.

\subsection{The Obstacles in Government-Society}

Affected by the traditional management methods and the old governance model, party committees, government departments and other traditional management organizations have issued strong orders, and the problems of "willful use of power" are still outstanding. As a result, the public, social organizations and other social governance subjects have weak power and "absence of vacancies". Especially at the "regulation" level, the supervision mechanism for the public, social organizations, and industry associations to participate in major social issues has not yet been established, and the supervision channels are still unblocked. It is difficult for the main body of social governance to play an effective role in the supervision field, so that the government sings "one-man play" and regulatory failures often occur. In the long run, the credibility of the government and government officials are greatly weakened, making it difficult for the public and social organizations to generate trust in the government and recognition of government actions, unwilling to actively participate in social governance, or even express their own needs in the wrong way, which seriously affects the 
process and effects of government functional transformation.

\section{The Next Step in Government Functional Transformation in the Context of the Reform of "Delegating Power, Strengthening Regulation, Improving Government Services"}

\subsection{Resolve Contradictions between Central and Local Governments and Improve the Integrity and Coordination of Governmental Work}

"Overall Party leadership must be implemented and upheld, while the people-centered, optimized, coordinated and efficient principle, as well as law-based governance must be upheld in deepening reform of Party and state institutions." (Xinhuanet, 2018). It is the core requirement for government functional transformation in the context of the reform of "Delegating Power, Strengthening Regulation, Improving Government Services". This means that governments at all levels and their leaders should establish an overall sense of consciousness and synergy, break the thinking limit of "separating the door", and systematically consider and plan the overall government functional transformation in the context of the reform of "Delegating Power, Strengthening Regulation, Improving Government Services", and overcome the drawbacks of government management such as segmentation and cross-responsibilities. At the same time, governments at all levels and their leaders are required to earnestly study the outstanding reform practice results represented by such measures as "one official seal to manage approvals", "up to one run", "one door and one window", and not only to learn their "form", more creatively combined with its own reform practices, to enhance cross-departmental, cross-level, and cross-disciplinary collaborative governance capabilities.

\subsection{Unleash Market Vitality and Let the Market Play the Decisive Role in Allocating Resources}

"The reform of 'Delegating Power, Strengthening Regulation, Improving Government Services' is in line with the great idea of market-oriented reform since the Third Plenary Session of the 11th Central Committee of the Communist Party of China. It is the continuation and development of the historical experience of 'relaxing and invigorating', and is an important part of perfecting the socialist market economic system and enriching practice." (Qin, 2019). "Delegating Power" is a summary and summary of the cancellation of government affairs that can be canceled by the government, and the decentralization of power that the government can delegate. So, governments at all levels and their leaders should correctly grasp the direction of reform, change the current self-interested behavior of the government as both "referee" and "athlete", fully stimulate market vitality, and fill the shortcomings of reform, especially the "soft power" of the business environment and public services has been continuously improved to 
create an "effective market" and "limited government".

\subsection{Improve Public Services and Build a People-Centric Service-Oriented Government}

The report of the 19th Communist Party of China National Congress puts forward, "We must transform government functions, deepen the simplification of government and decentralization, innovate supervision methods, enhance the credibility and execution of the government, and build a service-oriented government that the people are satisfied with." (Xinhuanet, 2017a). This requires governments at all levels and their leaders Change the "economic man" thinking mode and "official standard" behavior, establish a "people-centered" service concept, listen to the people's voice, solve the people's needs, change the original perfunctory responsibilities and delay implementation methods, improve efficiency and effectiveness, and provide more and better public services for the whole society. On the one hand, continue to improve the construction of government service halls and implement the "three concentrated, three in place" actions; on the other hand, vigorously promote the "Internet+ government services" model to promote the intelligent development of government services.

\section{Conflicts of Interest}

The author declares no conflicts of interest regarding the publication of this paper.

\section{References}

China Information Network (2019). Internet+ Government Services: Create New Models to Make Government Services Smarter. http://www.gov.cn/xinwen/2019-02/18/content_5366835.htm

National Business Organization (2019). Important Reference! Analysis of the Operational Dimensions of the Administrative Approval Bureau Model. http://www.sohu.com/a/275565604_99919028

Qin, C. J. (2019). The Problems and Countermeasures in the Reform of "Decentralization of Service"-Based on the Investigation and Thinking of Henan. Zhongzhou Academic Journal, 3, 1-7.

Shen, R. H. (2018). The Key Point of Deepening the Reform of "Delegating Service" in the New Era. http://m.sohu.com/a/225140586_115239

Xinhua News Agency (2017). Li Keqiang's Speech at the National Televised Conference on Deepening the Simplification of Government, Decentralization, Decentralization, Combined with Optimized Services. http://www.xinhuanet.com/2017-06/29/c_1121236906.htm

Xinhuanet (2017a). The Reform of Administrative Examination and Approval Continues to Deepen the Cancellation of More Than 800 "Wonderful Certificates". https://finance.sina.com.cn/roll/2017-09-29/doc-ifymkxmh7883065.shtml

Xinhuanet (2017b). Deepen the Simplified Administration and Decentralization to Reflect Service Administration. http://opinion.people.com.cn/n1/2017/1228/c1003-29732592.html

Xinhuanet (2018). People's Daily Commentator: Firmly Grasp the Principles of Deepen- 
ing the Reform of the Party and State Institutions-Second Discussion on Learning and Implementing the Spirit of the Third Plenary Session of the 19th Central Committee of the Party. http://www.xinhuanet.com/politics/2018-03/01/c_1122473861.htm 